\title{
Compliance and Comparability in a Cross-National Survey
}

\author{
Tom Emery ${ }^{1}$ and Arianna Caporali ${ }^{2}$ \\ ${ }^{1}$ Netherlands Interdisciplinary Institutes (NIDI), Netherlands \\ ${ }^{2}$ National Institute for Demographic Studies (INED), France
}

December 19, 2019

I n this paper, we analyze data from the Generations and Gender Programme (GGP) to examine whether comparability in cross-national data leads to greater scientific activity and outputs. Launched in 2000 by the United Nations Economic Commission for Europe (UNECE), the GGP is a longitudinal comparative survey of 18-79 year olds in 20 countries in Europe and beyond, run by a consortium of research institutions. It is based on a relatively decentralized management model and relies on considerable post-hoc harmonization of data. The international "core" questionnaire is either adapted to the different national contexts or partly incorporated into existing surveys. Using data from the surveys administration, we examine the quality of compliance and standardization in the GGP and whether this affects data usage. Firstly, we analyze the extent to which instruments from the core questionnaire were fielded within each of the countries in the GGP. The results show that on average across countries, $66 \%$ of instruments in the core questionnaire were captured but this varies widely from $23 \%$ to $84 \%$. Secondly, we take administrative data from the GGP website to capture the number of times each country dataset is downloaded, and we study whether those countries with greater compliance are more likely to be used in scientific analysis. We supplement this with the number of times a country dataset is used in peer reviewed comparative publications and cited in scientific articles. The paper concludes with some reflections on the analysis of compliance and usage in assessing the interest of comparative projects.

\section{Introduction}

What is the added value of comparative research within the social sciences? International organizations have in vested considerably in collecting and distributing comparable cross-national data. Even in long established national surveys such as the British Household Panel (Understanding Society), the German Socio-Economic Panel or the Panel Study of Income Dynamics, efforts have been made to make data more comparable and to enable international research. The value of doing so has always, however, been largely theoretical and hard to quantify. Assessing the impact of specific data collections on a scientific field is, indeed, difficult to achieve, without a hypothetical and counterfactual assumption as to what publications would have occurred regardless of such data being available and comparable. To the best of our knowledge there has been no attempt to date to identify the impact of comparable data on scientific output. This is somewhat strange given that the cost of ensuring comparability and collecting such data is vast.

In the last 30 decades, there has been a growing number of "deliberately designed comparative surveys" (Harkness et al. 2010: 4). Projects such as the International Social Surveys Programme (ISSP), the World Values Surveys (WVS), the Survey of Health, Ageing and Retirement in Europe (SHARE), the European Social Survey (ESS) have been run in an increasing number of countries. Comparative studies allow for policy learning, economies of scale, and best practice sharing. Yet they may differ in the extent to which their design is comparative including such aspects as sampling, questionnaire design, data collection mode, documentation, or harmonization (Harkness et al. 2010). In general, 
such factors depend on the surveys level of centralization in management. For example, surveys based on a centralized management model are more heavily involved in the implementation and enforcement of tendering and fieldwork guidelines to ensure that processes are comparable across countries. By contrast, other multi-national surveys operate on a highly decentralized basis where national teams are responsible for many aspects of the data collection and processing procedures. The comparability of a comparative survey therefore requires its compliance levels to be demonstrated and this cannot be assumed simply on the basis of their methodological guidelines.

Launched by the UNECE in 2000, the Generations and Gender Programme (GGP) is a longitudinal, crossnational panel study of 18-79 years old in 20 countries in Europe and beyond ${ }^{1}$ run by a consortium of research institutions ${ }^{2}$. It is aimed at studying the major demographic and economic challenges such as population ageing, low fertility, increased life expectancy and changes in family structures (Gauthier and Emery 2014). To do so, it conducts national, comparative, longitudinal surveys on individuals' demographic behaviors along their life courses (Vikat et al. 2007), and it complements the micro-level data with a contextual database that includes macro-level socio-economic and political indicators (Caporali et al. 2016).

The GGP surveys have been based on a relatively decentralized management model and relied on a considerable post hoc harmonization of data ${ }^{3}$. Defined by the central coordination team, the survey instruments and guidelines (UNECE 2005, 2007) were either adapted to the different national contexts or partly incorporated into existing surveys (such as in the case of Italy, Australia and Hungary; Gauthier, Cabaço and Emery 2018) ${ }^{4}$.

Previous works have focused on assessing GGP data quality, sampling and fieldwork methods (Fokkema et al. 2016), and on presenting the main strengths, weaknesses and perspectives of the GGP surveys (Gauthier, Cabaço and Emery 2018). This paper examines the extent to which questionnaire standardisation affects data usage: Does compliance with the GGP "core" questionnaire lead to greater data usage and scientific output? We assume that compliance to the core questionnaire has no effect on the number of times a country-dataset is downloaded from the data access platform, given that users would not know at the outset

\footnotetext{
${ }^{1}$ The countries in the GGP are: Austria, Australia, Belarus, Belgium, Bulgaria, Czech Republic, Estonia, France, Germany, Georgia, Hungary, Italy, Japan, Lithuania, Netherlands, Norway, Poland, Romania, Russia, Sweden.

${ }^{2}$ For more information on the GGP, visit the GGP website (hrefhttp://www.ggp-i.org/http://www.ggp-i.org/).

${ }^{3}$ See Granda, Wolf and Hadorn (2010) for a classification of different approaches to harmonization of survey data.

${ }^{4}$ The next round of GGP data collection, called GGP 2020, will be based on a more centralized methodology and a revised questionnaire (for more information see the GGP website and Gauthier, Cabaço and Emery 2018). Pilot surveys have already been carried out in Belarus, Croatia, Germany, Kazakhstan, and Portugal.
}

what the compliance level is. Instead, downloads more accurately reflect demand for specific country data. Higher compliance levels, on the contrary, are thought to lead to more comparative publications and more citations on those publications. The analysis has implications for a wide range of comparative surveys that invest considerable amounts of resources in ensuring comparability. This analysis attempts to ascertain the degree to which this investment is justified in terms of scientific outputs. If the aim of large scale comparative survey projects is the advancement of social science, then it should follow that the number of publications and their scientific impact should be one measure by which we can judge them to be successful or not.

We start with a brief overview of the development of comparative cross-national research and comparative survey methodology and the arguments in support of them. We then describe the data that we use: the level of compliance to the GGP "core" questionnaire of each country dataset, and the numbers of times each country dataset is downloaded, used in peer reviewed comparative publications and cited in scientific articles. We consider the association between these variables in Ordinary Least Squares (OLS) regressions, together with a number of control variables. We conclude with a discussion on the analyses of compliance and usage, to evaluate the potential added value of investing in comparative surveys.

\section{Literature Review}

Comparative cross-national research has historically proved useful for "translating 'grand theory' into empirically workable typologies of macro-settings for variations in human behavior" (Rokkan 1993: 34). More recently, emphasis is given to its insights regarding country contextual (i.e., structural and institutional) differences (Hantrais 1995). Since the twentieth century, comparative cross-national research proved to be useful also from a non-scientific perspective and started to receive greater governmental funding. For example, during World War II and its aftermath, it was used to study the psychological effects of the war, as well as propaganda (Mohler and Johnson 2010). Particularly since the 1970s, it increased its relevance and impact as a means to understand policy initiatives and their transferability to other states (Hantrais 1995). During the last three decades of the twentieth century, crossnational comparative surveys expanded in scope and country coverage (Smith 2010; Szalai 1993).

These arguments have fostered the development of methods to collect cross-national comparable data and to produce databases for comparative analyses. Since World War II, greater governmental funding accelerated this development (Mohler and Johnson 2010). The improvements in the machinery for treating big databases and the growth of sample survey organizations also played a central role, together with the 
creation of data archives (Rokkan 1993). With the establishment of the first internationally coordinated survey programs in the 1970s (e.g., the Eurobarmeter program), significant methodological and organizational progresses took place (Smith 2010).

There are however a number of issues that are inherent to comparative cross-national projects and which may affect the comparability of the data (Hantrais 1995; Scheuch 1993; Smith 2010; Szalai 1993). Problems may be encountered in the organization as well as in the execution of survey projects. For example, country participation is welcome even if the methodological requirements are not met. The financial resources to run the fieldwork can differ from one country to another leading in some cases to a reduction of the sample size and/or of the length of interviews. Most of all there may be semantic and/or conceptual misunderstandings and translational issues (Mohler and Johnson 2010; Szalai 1993). Equivalent measures seem to be yet empirically untenable, while comparability and similarity still remain the only possible goals (Mohler and Johnson 2010). From a conceptual point view, theoretical paradigms have been elaborated to minimize measurement errors and maximize measurement equivalence ${ }^{5}$.

International research associations, conferences and workshops are devoted to find methodological solutions and improve comparable surveys ${ }^{6}$. These initiatives demonstrate that a great deal of work has been put into enhancing comparability across surveys. By contrast, less endeavour has been devoted to evaluate whether investing in comparative survey methods does pay off in terms of scientific outputs. This is precisely the aim of this article.

\section{Data \& Methods}

In this paper we focus on the analysis of compliance and usage of the GGP survey datasets ${ }^{7}$. We use the first wave datasets available as of June $30^{\text {th }} 2015$ (17 countries $^{8}$ ). We use three types of data: levels of compliance to the GGP questionnaire, indicators pertaining to their usage, and control variables from a variety of sources.

\footnotetext{
${ }^{5}$ For example, Smith (2019) proposes a theoretical model to minimize the "comparison error".

${ }^{6}$ For example, see the contributions of the Multinational, Multiregional, and Multicultural Contexts (3MC) research community (Johnson et al. 2019).

${ }^{7}$ This paper uses data from the GGS Waves 1 (DOIs: 10.17026/dans-z5z-xn8g, 10.17026/dans-xm6-a262), see Gauthier, Cabaço and Emery (2018) or visit the GGP website (https://www.ggp-i.org/) for methodological details.

${ }^{8}$ We include countries with a level of compliance greater than $20 \%$ and available to users for at least a year at the time of writing.
}

\subsection{Levels of Compliance}

Based on the total number of variables in the pooled dataset (i.e., the dataset containing all variables for each country), we calculate the compliance as the percentage of variables included in each country dataset. The Generations and Gender Survey (GGS) core questionnaire was issued in 2003 and distributed to national teams who were asked to field the survey as close to the core questionnaire as possible. On average across countries, $66 \%$ of instruments in the core questionnaire were captured. This ranges from $23 \%$ for the Netherlands to $84 \%$ for Bulgaria (Figure 1). We distinguish between two types of compliance: a) "Compliance I" (the dark green histograms in Figure 1) that excludes variables having country-specific response categories, b) "Compliance II" (the light green histograms in Figure 1) that includes variables having country-specific response categories. In both types of compliance, we do not consider the variables that were asked only in specific countries.

There are many reasons for non-compliance. First, countries may find specific questions inappropriate in their given cultural context. The GGP includes a considerable number of such questions, given its focus on sexual behavior, relationship disagreements, domestic violence, and homosexuality. These questions were often excluded by more conservative countries, particularly in Eastern Europe. Nevertheless, as a total proportion of all variables in the survey, they are relatively few and this would not likely be driving large scale non-compliance.

The second reason for non-compliance is the issue of cost and interview length. The GGP contains a number of loops and grids which can rapidly extend the length of interview in particular cases. For example, respondents must answer a series of questions on each of their children. For respondents with large numbers of children (the highest recorded is 16), this means answering the entire series for each child. National teams therefore unilaterally dropped questions from these series in order to reduce the impact of such loops. This was particularly true in countries that used a Paper and Pencil Interview (PAPI). In the case of children for example, many countries opted to omit questions regarding whether parental leave was taken when that child was born. This reduction in loops represents a considerable portion of non-compliance.

The third reason is national questionnaire prioritization. The design of the GGS follows a long run tradition in the social sciences of surveys examining relationships, fertility and family formation, with the majority of European countries administering some form of survey on these issues by the early 1990's. The Fertility and Families Surveys (FFS) of the early 1990's was a project coordinated by the UNECE in order to harmonize these national level efforts that would eventually develop into the GGP. However, some of the national surveys had established long running 


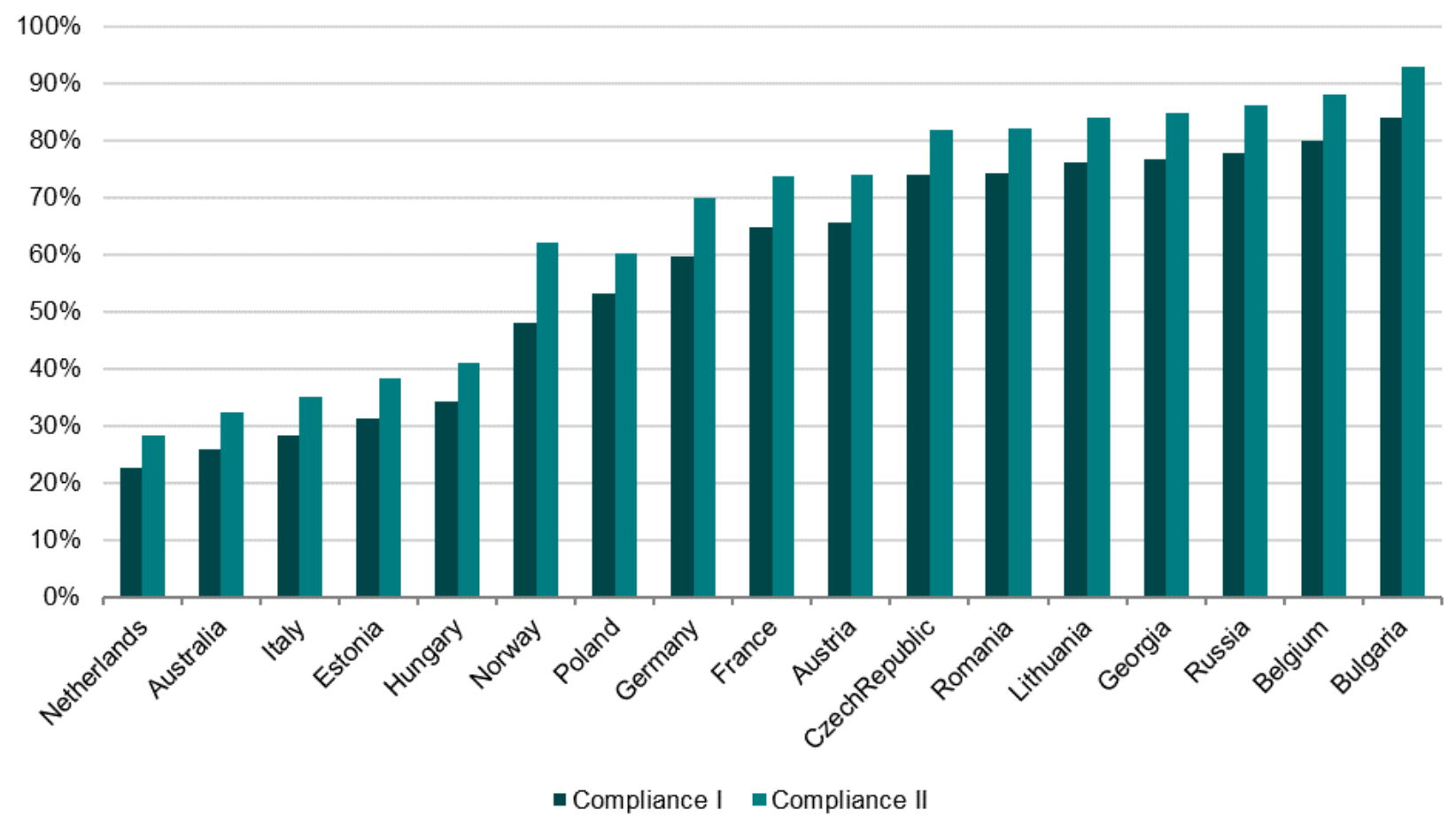

Figure 1: Compliance in the First Wave of the Generations and Gender Survey.

Note: Compliance I: without country-specific values; Compliance II: with country-specific values.

time series within their country and were reluctant to adapt questionnaire designs for comparability across countries at the expense of national level time-series. Questions regarding fertility and family planning were specifically affected by this, leading to a high degree of divergence across countries. This was exacerbated by the design of the GGS, which included many filters for questions on fertility that were not present in the FFS or national surveys. These filters affect the universe of certain questions in the GGS by restricting the population to which the question is posed. For example, in the GGS the question as to whether someone intends to have children in the next 3 years is limited only to those who have explicitly said that they have previously had sex. In some national level surveys the question of whether the respondent had had sex was not asked, and therefore the universe on the question of fertility intention was not comparable.

The fourth reason is that the GGP design created a tension between measurement standards that forced national teams to comply either with the GGP core questionnaire or with the prevailing international standard. This was particularly evident with regards to the measurement of income, labour market activity, employment sector (ISCO) and education (ISCED). The GGS design was not always in compliance with Eurostat, the International Standardization Office (ISO) or the International Labor Organization (ILO) standards in this regard. Therefore, many national teams deviated from the central questionnaire either to comply with international standards or to comply with national standards.

The fifth reason is what we refer to as national initiative. The management of the GGP fieldwork was highly decentralized and there was limited contact between the central coordination and many of the fieldwork teams during the data collection process. This led to national teams addressing practical and technical issues in a unilateral manner and consequently eroding the comparability of the data. For example, if piloting revealed an interview length that was beyond budget constraints, national teams would likely make decisions as to what elements to drop based on their own considerations, rather than in consultation with the central coordination team. Similarly, response categories were often not applicable to specific country contexts, and national teams unilaterally reconfigured response categories or even entire questions in order to better reflect the national context. A good example of this would be in questions related to childcare usage, where the institutions vary in nature and name. In these cases, comparability is difficult to achieve multilaterally, but virtually impossible if national teams act unilaterally to define concepts.

These five reasons are the main factors that appear to have driven low compliance in the GGP. Based on this overview it may appear that the coordination of the GGP was problematic or deficient. This perception should be contested. The central coordination of the GGP was greatly under, and yet has managed to coordinate a fair degree of comparability through pre- and post- harmonization of questionnaire instruments. The 


\begin{tabular}{llll} 
& \multicolumn{3}{c}{ Publication } \\
Country & Downloads & Count & Citations \\
\hline Australia & 312 & 10 & 24 \\
Austria & 590 & 33 & 87 \\
Belgium & 500 & 27 & 101 \\
Bulgaria & 675 & 72 & 267 \\
Czechia & 119 & 17 & 112 \\
Estonia & 426 & 26 & 102 \\
France & 848 & 95 & 550 \\
Georgia & 525 & 49 & 226 \\
Germany & 897 & 67 & 294 \\
Hungary & 684 & 43 & 215 \\
Italy & 482 & 36 & 112 \\
Lithuania & 275 & 34 & 113 \\
Netherlands & 657 & 32 & 236 \\
Norway & 553 & 39 & 296 \\
Poland & 182 & 12 & 80 \\
Romania & 586 & 46 & 301 \\
Russia & 519 & 80 & 337
\end{tabular}

Table 1: Usage Information

efforts of the GGP have brought some degree of coordination where little existed before, but have stopped short of imposing a centralized survey model. The consequences of this are however that compliance was greater in some countries compared to others. This provides something of a natural experiment which allows us to examine whether those national teams that did comply with the central model were rewarded with greater scientific usage and impact.

\subsection{Measuring usage}

To account for data usage, we consider the number of times each country dataset has been downloaded from the GGP data platform since it was initially made available (Table 1). In order to download the data, users must register on the GGP website and apply for the data they would like to access. They are then required to sign a data usage agreement, after receipt of which the data is made available to them in the online data portal. One important distinction is that the figure we use is of data downloads and not successful data applications. Many users simply apply for data from all countries and we were keen to identify which specific data they intended to use. We therefore opted to use the number of downloads for each country dataset. Up until February 2014, the data was only available in separate country files and so users would have to actively download the data for countries they wished to analyze, rather than downloading a file with all countries and then discarding countries they didn't want to analyze. Even after February 2014, countryspecific datasets continued to be provided in addition to the pooled datasets. This therefore provides us with a relatively clear and robust indicator of data usage and interest that is specific to each country.
We also examine the number of peer reviewed comparative publications (journal articles and book chapters; Table 1) recorded via the GGP website. The GGP website records all publications that use the GGP data by monitoring publications through google scholar and web of science. The coordination team is notified when new publications appear which include the terms "GGP", "GGS", "Generations and Gender Survey" or "Generations and Gender Programme". The coordination team then assesses the publications and examines whether they include analysis based on GGP data. If the publication does include analysis using GGP data, it is added to the bibliography. We coded the resulting bibliography to count the number of times a country dataset is used in publications. We then supplemented this with the total GGP citations (Table 1) which were extracted from Google Scholar using Harzing's Publish or Perish software (www.harzing.com) on $30^{\text {th }}$ June 2015. The bibliography used for analyses can be provided upon request.

\subsection{Controls}

The third set of variables is derived from GGP data documentation and from various international sources (Table 2). This information is used as controlling variables in our analysis. We consider the year of fieldwork ${ }^{9}$ and the number of months the country-datasets have been available from the GGP website up until May 2015. We would expect that countries where the data has been available for longer would have had more publications and those publications would have garnered more citations. We also include the number of members of the International Union for the Scientific Study of Population (IUSSP) per country as an indicator of

\footnotetext{
${ }^{9}$ Operationalized as the number of years since 2004.
} 


\begin{tabular}{|c|c|c|c|c|c|c|}
\hline Country & $\begin{array}{l}\text { Fieldwork } \\
\text { Year }\end{array}$ & $\begin{array}{l}\text { Years } \\
\text { Available }\end{array}$ & $\begin{array}{l}\text { IUSSP } \\
\text { Members } \\
(2014)^{1}\end{array}$ & $\begin{array}{l}\text { Doctoral } \\
\text { Pop. } \\
(2013)^{2}\end{array}$ & $\begin{array}{l}\text { Population } \\
\text { in } 2014 \\
(, 000)^{3}\end{array}$ & $\begin{array}{l}\text { GDP Per } \\
\text { Capita } \\
\text { (PPP) } \\
(2014)^{4}\end{array}$ \\
\hline Australia & 2005 & 3.38 & 36 & 52,317 & 23,470 & $€ 43,219$ \\
\hline Austria & 2008 & 4.53 & 10 & 25,657 & 8,546 & $€ 43,906$ \\
\hline Belgium & 2008 & 3.50 & 18 & 14,610 & 11,231 & $€ 40,885$ \\
\hline Bulgaria & 2004 & 5.18 & 0 & 5,371 & 7,224 & $€ 16,048$ \\
\hline Czechia & 2005 & 1.05 & 5 & 25,194 & 10,525 & $€ 28,695$ \\
\hline Estonia & 2004 & 4.29 & 0 & 3,044 & 1,315 & $€ 25,865$ \\
\hline France & 2005 & 5.18 & 67 & 69,535 & 65,984 & $€ 37,214$ \\
\hline Georgia & 2006 & 5.18 & 2 & 4,266 & 4,504 & $€ 7,233$ \\
\hline Germany & 2005 & 5.18 & 17 & 213,200 & 80,971 & $€ 43,444$ \\
\hline Hungary & 2004 & 5.18 & 0 & 7,332 & 9,863 & $€ 23,609$ \\
\hline Italy & 2003 & 3.45 & 32 & 34,928 & 60,789 & $€ 33,078$ \\
\hline Lithuania & 2006 & 2.98 & 1 & 2,681 & 2,932 & $€ 25,708$ \\
\hline Netherlands & 2002 & 5.18 & 17 & 13,631 & 16,865 & $€ 45,281$ \\
\hline Norway & 2007 & 4.53 & 8 & 7,407 & 5,137 & $€ 64,020$ \\
\hline Poland & 2010 & 1.62 & 2 & 42,295 & 38,012 & $€ 23,952$ \\
\hline Romania & 2005 & 5.18 & 1 & 21,356 & 19,904 & $€ 18,569$ \\
\hline Russia & 2004 & 5.18 & 9 & 160,841 & 144,967 & $€ 23,293$ \\
\hline
\end{tabular}

Table 2: Controls used (data retrieved in November 2015).

(1) Source: IUSSP secretariat.

(2) Source: (c) Eurostat, 1995-2015, except otherwise indicated. For Australia, Georgia and Russia: UNESCO Institute for Statistics, http://data.uis.unesco.org/. Data for Australia, Georgia and Russia refer to 2012.

(3) Source: (C) Eurostat, 1995-2015, except otherwise indicated. For Australia: Australian Bureau of Statistics, 2015, Estimated resident population, by age and sex-at 30 June 2014, Excel spreadsheet, Cat. No. 31010DO002.201503, viewed 06/11/2015, https://www.abs.gov.au/AUSSTATS/abs@.nsf/DetailsPage/3101.0Mar 2015. For Georgia: The World Bank: World Development Indicators (WDI): GeoStats. Eurostat data correspond to the average population. France, Hungary and Romania: data are provisional. France: data include overseas territories. Australia: data refer to mid-year. Georgia: data are adjusted to mid-year population using geometric mean for the years where mid-year population figures are not available, and exclude Abkhazia and South Ossetia.

(4) Source: World Development Indicators: World Bank, International Comparison Program database.

the size of the research community in that country with a substantive interest in the data. Additionally, to indicate a broader sense of how large and well-resourced a country research community is, we take into account the population with ISCED 8 (i.e., the education level doctoral or equivalent), the total population, and GDP per capita. We would anticipate that a more resourced and larger research community would lead to a larger number of publications and citations.

\subsection{Method}

We run OLS regressions to assess the association between compliance and downloads and the number of comparative publications whilst controlling for several potentially confounding factors. We also consider each section of the questionnaire separately and estimate their contribution to publications, to enable us to examine whether the issue of compliance is variable depending on the subject matter covered within specific sections of the questionnaire. For example, a subject such as income is a pervasive and common variable within social scientific analyses and a lack of compliance in this area may have a greater impact on publications than the section on attitudes and values, for example.

\section{Results}

To assess if variation in the compliance levels was associated with various indicators of scientific activity, we ran three OLS models predicting the number of downloads, the number of publications and the number of citations. The results are presented in Table 3. For all three dependent variables, we ran multiple iteractions of the model, excluding and including our controlling variables. The coefficients in all models were, however, largely unaffected in their magnitude and no significance levels changed.

Regarding downloads, the coefficient was positive, suggesting that with each percentage increase in compliance there would be one further download. However, this was not statistically significant. The key determinant of downloads appears to be the number of months the data has been available. This suggests that for every month that passes each country dataset is downloaded 


\begin{tabular}{|c|c|c|c|c|c|c|}
\hline & Downloads & & Publications & & Citations & \\
\hline Compliance & $\begin{array}{c}1.001 \\
(1.519)\end{array}$ & & $\begin{array}{c}0.548 \\
(0.173)\end{array}$ & $*$ & $\begin{array}{c}2.584 \\
(1.523)\end{array}$ & \\
\hline Year of Fieldwork & $\begin{array}{c}-6.026 \\
(16.687)\end{array}$ & & $\begin{array}{c}-2.149 \\
(1.904)\end{array}$ & & $\begin{array}{c}-10.092 \\
(16.730)\end{array}$ & \\
\hline Months Available & $\begin{array}{l}10.866 \\
(1.783)\end{array}$ & $* * *$ & $\begin{array}{c}0.809 \\
(0.203)\end{array}$ & $* *$ & $\begin{array}{c}4.355 \\
(1.787)\end{array}$ & * \\
\hline IUSSP Membership & $\begin{array}{c}2.920 \\
(1.752)\end{array}$ & & $\begin{array}{c}0.338 \\
(0.200)\end{array}$ & & $\begin{array}{c}2.103 \\
(1.757)\end{array}$ & \\
\hline Population with ISCED 8 & $\begin{array}{c}0.001 \\
(0.001)\end{array}$ & & $\begin{array}{c}0.000 \\
(0.000)\end{array}$ & & $\begin{array}{c}0.000 \\
(0.001)\end{array}$ & \\
\hline Population in 2014 (000's) & $\begin{array}{c}-0.002 \\
(0.001)\end{array}$ & & $\begin{array}{c}0.000 \\
(0.000)\end{array}$ & & $\begin{array}{c}0.001 \\
(0.001)\end{array}$ & \\
\hline GDP Per Capita (000's) & $\begin{array}{c}0.001 \\
(0.002)\end{array}$ & & $\begin{array}{c}0.000 \\
(0.000)\end{array}$ & & $\begin{array}{c}0.001 \\
(0.002)\end{array}$ & \\
\hline Constant & $\begin{array}{c}-155.317 \\
(145.908)\end{array}$ & & $\begin{array}{c}-34.830 \\
(16.646) \\
\end{array}$ & & $\begin{array}{c}-226.90 \\
(146.280)\end{array}$ & \\
\hline $\begin{array}{l}\mathrm{N} \\
\mathrm{R} \text { Squared }\end{array}$ & $\begin{array}{c}17 \\
0.877\end{array}$ & & $\begin{array}{c}17 \\
0.874\end{array}$ & & $\begin{array}{c}17 \\
0.679\end{array}$ & \\
\hline
\end{tabular}

Table 3: Results of OLS Regressions

Note: $*=0.05 ; * *=0.01 ; * * *=0.001$

more than 10 times. This would appear to be the crucial factor explaining variation in usage given that the $\mathrm{R}$ squared value is reduced to just 0.37 when it is excluded. As well as high variation in compliance, the GGP also has a considerable degree of variation in the processing time of data and subsequently the amount of time it has been available to researchers. For example, fieldwork in the Czech Republic was completed in 2005 but the data was not released to the research community until 2014, reducing the amount of time it has been available to researchers. None of the indicators we included as controls were significant which suggests that potential spurious effects are unlikely. For publications, the results suggest that compliance does have a significant effect on scientific output at a 95\% confidence level. This would suggest that for each additional 2 percentage points of compliance, it could be expected that a further peer-reviewed publication would follow. To put this in context the maximum effect size, based on estimated effects of compliance at the $5^{\text {th }}$ and $95^{\text {th }}$ percentile, would be 30 publications in which national data featured. This accounts for approximately $17 \%$ of variation in the number of publications a national data set produces. Again, we see some effect of the time for which the data has been available which suggests that a new peer-reviewed publication appears for each month that passes for each national data set. As with the data downloads, none of the controls we included were significant and the coefficients were robust to a wide battery of indicators. The citations accrued by publications including a national dataset did not appear to be affected by the degree of compliance. The effect size was relatively large with each additional percentage point in compliance leading to a further two and a half citations, however the standard errors of this estimation were considerable. Analysis with a larger sample size may remedy this but this is beyond the capacity of this limited analysis. As with downloads and publications, none of the indicators appeared to have any coherent association with the number of citations.

As well as viewing the survey as a whole, we also analysed the impact of compliance in each section by replacing the overall indicator of compliance with section specific indicators. The results of this analysis on the number of publications can be seen in Figure 2. The results are highly varied and indicate that compliance levels in sections 1 and 3 actually have a negative and significant association with the number of publications. This would suggest that greater compliance in these sections actually reduced the number of publications. These sections are those on general information and partnerships. This is intriguing given that these are two central sections upon which a considerable number of GGP publications are based. The reasoning for this is unclear. The effect of compliance is significant and positive in four sections: Fertility, Health, Partners Income and Household Income. Fertility is a core theme of the GGP and one section that differentiates the GGP from other general surveys such as the European Social Survey, EU-SILC and European Quality of Life Survey and so its effect is unsurprising. Health and the two income sections provide key controls that are essential to a large number of social analyses.

\section{Discussion}

The analyses show that compliance does not affect downloads or citations, while for every $2 \%$ of compli- 


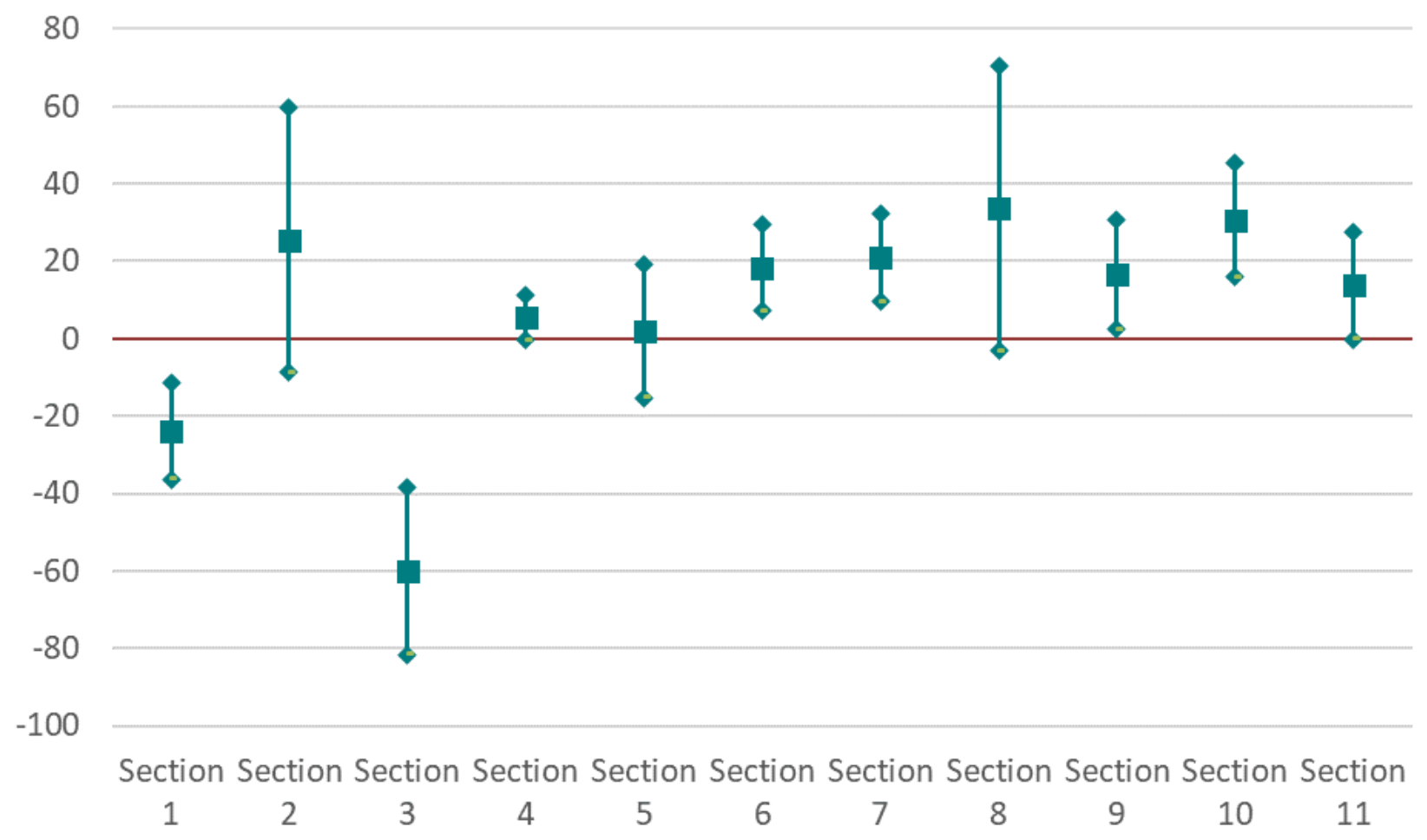

Figure 2: Marginal Effects of Compliance by Section (95\% Confidence Intervals)

Note: Sections refer to (1) General Information (2) Children (3) Partnerships (4) Household Work (5) Parents (6) Fertility (7) Health (8) Personal Income (9) Partners Income (10) Household Income (11) Attitudes \& Values

ance there is an additional publication. Compliance to the questionnaire together with rapid availability of the datasets to the research communities appears to be a key component of success in terms of scientific output. These results suggest that the association between compliance and scientific output is driven by the added value of cross-national data, rather than being due to spurious factors such as the size of the research community in a specific country or the degree of interest in data from a specific country. If interest in specific fields was driving both compliance to an international project and then subsequent publications on a topic from a given country, then we would expect to see an effect of compliance appearing in downloads as well as in publications. Instead the lack of an effect of compliance on downloads suggests that researchers are downloading and accessing the data in a process that is independent of those that drive compliance. In short, we are not seeing active and internationally minded national research communities complying to an international project and then publishing using their own countries data.

Before we try and extrapolate from these results to make broader conclusions it is necessary to consider the limitations of the analysis. Firstly, whilst the GGP offers an interesting 'natural experiment' in the value of complying to an international project, the analysis is not immune to issues such as omitted variable bias or endogeneity. To overcome some of these issues it would be desirable to examine the usage of multiple datasets within a single country over time in order to better separate out country effects and the actual effect of compliance. Unfortunately, such an approach was not possible in this instance as the GGS doesn't have multiple datasets from each country. It does have multiple waves of data for a number of countries, but compliance and usage between waves is so closely related as to render such analysis impossible. Analysis of data from other survey infrastructures would certainly help mitigate this limitation but falls outside the scope of the analysis conducted here.

Secondly, this data only represents a single data infrastructure, and a relatively small one at that. Replication of the analysis with regards to similar infrastructures would be necessary before very concrete conclusions could be drawn. What makes it difficult to replicate this analysis is the limited number of comparative research projects in which there is a high variation in the level of compliance and, simultaneously, a sufficient enough data infrastructure to document data usage. Nevertheless, we would strongly encourage comparative projects to make attempts at estimating the added value that the comparative perspective brings to their project, with regards to scientific output and impact.

Thirdly, the measurement of usage, output and compliance are relatively crude and extracted from an administrative data infrastructure that is not specifically designed to support such analysis. The data infrastruc- 
ture of the GGP is not one in which it is intuitive or easy to see the interrelationship between these various factors. A better understanding of usage would be provided through the ability to tie the downloading of specific datasets to specific publications, and even to the usage of specific variables. There is an increasing emphasis within the social sciences of accurate cataloguing and indexing across the research life cycle. The ability to more accurately map and track the production of scientific outputs would empower data infrastructures to better appraise their own work and understand where their contribution to the scientific community lies.

Despite these limitations, we feel the analysis offers an indication that the comparative efforts of projects such as the GGP, do lead to greater scientific output. Data from countries where compliance was high led to a greater number of scientific publications, and this is a strong indication of added value. Regarding impact, the results were not conclusive and the strong effect of timing would perhaps indicate that time is required for any effect of compliance on impact to be distilled. At this stage, however, there is very limited evidence of increased impact. The analysis is however only a preliminary one and, to the best of the authors' knowledge, not one that has been published elsewhere. Further research, particularly with better monitoring of the research process, would enable more powerful analysis that could help identify ways in which crossnational data infrastructures could benefit the scientific community.

\section{Bibliography}

- Caporali, A., Klüsener, S., Neyer G., Krapf, S., Grigorieva, O., and Kostova, D. (2016). The Contextual Database of the Generations and Gender Programme: Concept, Content and Research Examples. Demographic Research 35(9): 229-252. DOI: http://dx.doi.org/10.4054/DemRes.2016.35.9.

- Fokkema, F., Kveder, A., Hiekel, N., Emery, T., and Liefbroer, A. (2016). The Generations and Gender Programme Wave 1: Sampling and Weighting. Demographic Research 34(18): 499-524. DOI: http://dx.doi.org/10.4054/DemRes.2016.34.18.

- Gauthier, A.H., Cabaço, S.L.F., and Emery, T. (2018). Generations and Gender Survey Study Profile. Longitudinal and Life Course Studies 9(4): 456-465. DOI: http://dx.doi.org/10.14301/llcs.v9i4.500.

- Gauthier, A.H. and Emery, T. (2014). Generations and Gender Programme: A Research Infrastructure for Analysing Relationships over the LifeCourse. In: Duşa, A., Nelle, D., Stock, G., and Wagner G. (eds.). Facing the Future: European Research Infrastructures for the Humanities and Social Sciences. Berlin: SCIVERO Verlag: 99-108.

- Granda, P., Wolf, C., and Hadorn, R. (2010).
Harmonizing Survey Data. In: Harkness, J.A., Braun, M., Edwards, B., Johnson, T.P., Lyberg, L., Mohler, P.P., Pennell, B.-E., and Smith, T.W. (eds.). Survey Methods in Multinational, Multiregional, and Multicultural Contexts. Hoboken, N.J.: Wiley Sons: 315-332. DOI: http://dx.doi.org/10.1002/9780470609927.ch17.

- Hantrais, L. (1995). Comparative Research Methods. Social Research Update 13, Summer 1995. (http://sru.soc.surrey.ac.uk/SRU13.html, last accessed 02/09/2019).

- Harkness, J.A., Braun, M., Edwards, B., Johnson, T.P., Lyberg, L., Mohler, P.Ph., Pennell, B.-E., and Smith T.W. (2010). Comparative Survey Methodology. In: Harkness, J.A., Braun, M., Edwards, B., Johnson, T.P., Lyberg, L., Mohler, P.P., Pennell, B.-E., and Smith, T.W. (eds.). Survey Methods in Multicultural, Multinational, and Multiregional Contexts. Hoboken, N.J.: Wiley Sons: 3-16. DOI: http://dx.doi.org/10.1002/9780470609927.ch1.

- Johnson, T.P, Pennell, B.-E., Stoop, I.A.L., and Dorer, B. (2019). The Promise and Challenge of 3MC Research. In: Johnson, T.P, Pennell, B.-E., Stoop, I.A.L., and Dorer, B. (eds.). Advances in Comparative Survey Methods: Multinational, Multiregional, and Multicultural Contexts (3MC). Hoboken, N.J.: Wiley Sons: 3-12. DOI: http://dx.doi.org/10.1002/9781118884997.ch1

- Mohler, P.P. and Johnson, T.P. (2010). Equivalence, Comparability and Methodological Progress. In: Harkness, J.A., Braun, M., Edwards, B., Johnson, T.P., Lyberg, L., Mohler, P.P., Pennell, B.-E., and Smith, T.W. (eds.). Survey Methods in Multinational, Multiregional, and Multicultural Contexts. Hoboken, N.J.: Wiley \& Sons: 17-29. DOI: http://dx.doi.org/10.1002/9780470609927.ch2.

- Rokkan, S. (1993). Cross-Cultural, Cross-Societal and Cross-National Research. Historical Social Research / Historische Sozialforschung 18(2): 6-54. DOI: http://dx.doi.org/10.12759/hsr.18.1993.2.6-54.

- Scheuch, E. K. (1993). Theoretical Implications of Comparative Survey Research: Why the Wheel of Cross-Cultural Methodology Keeps on Being Reinvented. Historical Social Research / Historische Sozialforschung 18(2): 172-195. DOI: http://dx.doi.org/10.12759/hsr.18.1993.2.172195.

- Smith, T.W. (2010). The Globalization of Survey Research. In: Harkness, J.A., Braun, M., Edwards, B., Johnson, T.P., Lyberg, L., Mohler, P.P., Pennell, B.-E., and Smith, T.W. (eds.). Survey Methods in Multicultural, Multinational, and Multi-regional Contexts. Hoboken, N.J.: Wiley \& Sons: 477-484. DOI: http://dx.doi.org/10.1002/9780470609927.ch25.

- Smith, T.W. (2019). Improving Multinational, Multiregional, and Multicultural (3MC) Comparability Using the Total Survey Error (TSE) 
Paradigm. In: Johnson, T.P, Pennell, B.-E., Stoop, I.A.L., and Dorer, B. (eds.). Advances in Comparative Survey Methods: Multinational, Multiregional, and Multicultural Contexts (3MC). Hoboken, N.J.: Wiley \& Sons: 13-43. DOI: http://dx.doi.org/10.1002/9781118884997.ch2.

- Szalai, A. (1993). The Organization and Execution of Cross-National Survey Research Projects. Historical Social Research/ Historische Sozialforschung 18(2): 139-171. DOI: http://dx.doi.org/10.12759/hsr.18.1993.2.139171.

- UNECE - UNITED NATIONS ECONOMIC COMMISSION FOR EUROPE (2005). Generations and Gender Programme - Survey Instruments. New York-Geneva: United Nations (http://www.unece.org/index.php?id=10864, last accessed 02/09/2019).

- UNECE - UNITED NATIONS ECONOMIC COMMISSION FOR EUROPE (2007). Generations and Gender Programme - Concepts and Guidelines. New York-Geneva: United Nations (https://www.unece.org/index.php?id=10892, last accessed 02/09/2019).

- Vikat, A., Spéder, Z., Beets, G., Billari, F., Bühler, C., Desesquelles, A., Fokkema, T., Hoem, J.M., MacDonald, A., Neyer, G., Pailhé, A., Pinnelli, A., and Solaz, A. (2007). Generations and Gender Survey (GGS): Towards a better understanding of relationships and processes in the life course. Demographic Research 17(14): 389-440. DOI: http://dx.doi.org/10.4054/DemRes.2007.17.14. 